\title{
A METHOD FOR STUDYING THE HESSIAN FLY AND OTHER INSECTS.*
}

\author{
By James W. MCCol.Loch,
}

Associate Entomologist, Kansas State Agricultural Experiment Station.

The following method for conducting life history studies was developed in connection with a study of the Hessian fly (Mayetiola destructer Say) and since then has been used for making detailed observations on the development of several other insects attacking the stem and leaves of various cereal crops. The fact that the Hessian fly larvæ develop between the leaf sheath and the stalk often below the surface of the ground has rendered it difficult to follow the growth of this stage. It has also been hard to observe the development of the eggs and the behavior of the larvæ on the leaf.

In 1916 , an attempt was made to grow the wheat plants in an artificial culture medium so that the entire plant would be exposed and accessible for observation. $\dagger$ Plant physiologists have long made use of water cultures in conducting experiments on the nutrient requirements of plants and other physiological relations and it seemed possible that with certain modifications this method could be extended to observations on insect life histories. In the Hessian fly investigations, the wheat was planted in soil or sand and allowed to grow to a height of two or three inches. The plants were then removed from the soil, the roots thoroughly washed to remove all soil particles, and then placed in wide-mouth bottles of $200 \mathrm{cc}$. capacity, containing about $150 \mathrm{cc}$. of the water culture (Fig. 1). One plant was placed in each bottle, the roots being immersed in the liquid and the stalk kept in position by being held lightly against one side of the neck of the bottle with a cotton stopper. The liquid

* Contribution from the Entomological Laboratory, Kansas State Agricultural College, No. 52. This paper embodies the results of some of the investigations undertaken by the writer in the prosecution of project No. 6 of the Kansas Agricultural Experiment Station.

† The writer wishes to acknowledge his indebtedness to $\mathrm{Mr}$. H. Yuasa for suggestions and aid in connection with this work. 
plant food used was that known to plant physiologists as Pfeffer's solution and is prepared as follows:

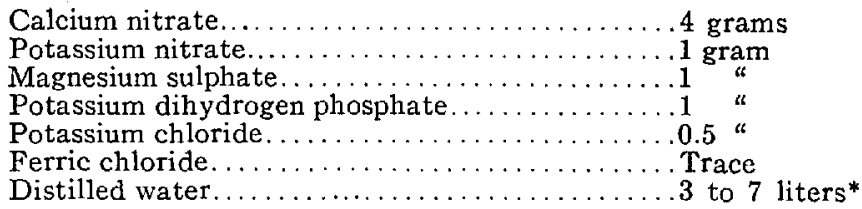

The plants grew well in this solution, although at times some difficulty was encountered by the growth of algæ in the liquid. This was largely overcome, however, by painting the bottles black. Usually the plants lived long enough for experimental purposes without changing the liquid. When the experiments were prolonged the solution was changed as often as necessary.

By using this method, it was possible to follow the life history of the Hessian fly from oviposition to the formation of the puparium. The plants could be handled conveniently and the various stages studied with greater ease and exactness than when the plants were grown in the soil. When necessary, the plants could be removed from the bottle and placed under the binocular for close study. By carefully shaving the epidermis of the leaf sheath, it was possible to keep the larvæ under observation at all times. As the larvæ increased in size they could readily be seen through the neck of the bottle.

This method proved so successful in the Hessian fly work that it was adopted for the study of a number of other insects infesting cereal crops. Thus far the writer has grown wheat, oats, rye, barley, corn,

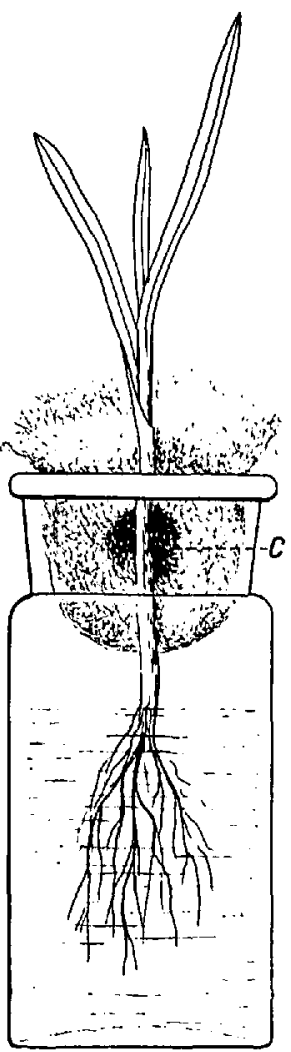

FIG. 1.

Wheat plant growing in a nutrient solution. $\mathrm{C}-$ Cell for confining insects on the plant. and many of the sorghums in Pfeffer's solution in connection with studies of the chinch bug (Blissus leucopterus Say), green

* The writer has found that five liters is best for the work under consideration. 
bug (Toxoptera graminum Rond) and corn leaf aphis (Aphis maidis Fitch).

Certain modifications in the method of handling the plants were necessary for these insects. In order to confine them on the stalks of the plants, a small cell was formed in one side of the cottun stopper (Fig. 1-c). The cotton fibers served as effective barriers in holding the insects in the cell and exact data could be obtained on molting and the length of instars, and, in the case of the aphids, on the number of young produced. This method was also used to study certain phases of activity of several parasites of the Hessian fly puparium. The parasites were confined in the cells with plants containing flaxseed in their natural position and the behavior and methods of oviposition of the parasites were easily observed. In a similar manner a study was made of the chinch bug egg parasite (Eumicrosoma benefice (jahan). Good results were obtained in confining leaffeeding insects on the leaves by inverting another bottle over the plant or by lowering the plant so as to bring a part of the leaf into the cell.

In conclusion, a brief summary is given of the more important advantages of this method of growing plants for life history studies.

1. By certain modifications this method may be enlarged to facilitate more extended observations on a much larger number of insects.

2. The manipulation of plants in a water culture has proved very satisfactory in growing most of the staple crops, it being casily done and facilitates handling the plants in making close observations.

3. This method is especially valuable where the work is done under constant conditions, since it eliminates the factor of variation in plant food.

4. The use of the water culture enables one to study many phenomena in the insect's life history that normally are difficult to observe and which often necessitate the destruction of the plant.

5. When plants are grown by this method, they may be removed and examined under the microscope or binocular without injury to the plant. 
6. Plants are often found in the field infested with some insect which it is desirable to rear to maturity. Such plants can be removed from the soil and kept alive in a water culture until the insect matures.

7. Many points in the life economy of parasites may be studied in detail with relation to the host. 